\title{
Renal Calyx and Pelvis
}

National Cancer Institute

\section{Source}

National Cancer Institute. Renal Calyx and Pelvis. NCI Thesaurus. Code C162216.

The portion of the kidney comprising the renal calices and pelvis. 